\title{
Exploration on the Individualized Expression of Chocolate Package Design
}

\author{
Chen Ling \\ College of Liberal Arts, Macau University of Science and Technology
}

\begin{abstract}
Today, when commodities are becoming homogenized gradually, the individualized expression of commodities has played a more and more important role in product sales. Chocolate packages also request the in-depth research about the individualized demands of consumption groups, focusing on children and young people, so their design can meet the aesthetic taste of consumers, thereby arousing the mental resonance of consumers and realizing the objective of product promotion.
\end{abstract}

Keywords-Exploration; Chocolate packages; Individuation; Expression

\section{INTRODUCTION}

Along with people's living standard being constantly improved and the consumers' food safety and health awareness being constantly reinforced, as a nutritious and healthy consumer product, chocolate has been accepted by more and more consumers, and selected as an important present to visit relatives and friends. Currently, chocolate industry develops fast with big market potential, but the chocolate in our country is also constantly making progress along with the development of era, and the individualized design of package has also become the current research topic attracting people's attention.

\section{CurRent Status on Chocolate PaCKage STRUCTURE}

There are various kinds of chocolate package in the current market, which can be summarized as knot type package, folding type package, pillow type package, etc. These different package structure forms are changed along with the industrial development of different eras, and traditional knot type package is the most original package form at that time, and it is completed on the basis of manual work, and the knot type package for traditional candy package is originated from traditional candy package, and some enterprises have introduced full-automatic mechanical package for such form of package, and some of them continuously implement manual work up till present; during 1960s-1970s, pillow type package started to prevail internationally, and in 1980s, it started to become popular at home, and such form of package was quite common in the market and has occupied a leading position.

\section{The DeVelopment TREnd Of ChOCOlAte PaCKAgE DESIGN}

Currently, the chocolate industry in developed countries has stepped into the modernized process, and new materials, new equipment and new technologies are promoting the chocolate production technique and package technology to constantly bring forth the new through the old, and highlight individualized pursuit; the chocolate package in our country has also constantly learned from the experience of foreign developed countries, and today is a world of internet, and the era of internet earth village, and the generation of new things will immediately extend all over the world. No matter it is the occurrence of new materials, or the occurrence of new breakthroughs in new equipment or new technology, our country will keep up with the step of era, and pursue perfection. The box types are diversified, and can meet consumers' demand, including modeling, assembly technique, paper texture, and paper sheet weight [1]. Creative package can attract the attention of consumers in the sales of commodity circulation, and strong visual impact can attract the purchasing desire of consumers, and pay attention to different aesthetics demands of target consumers under different age grades. When being compared with the package level in developed countries, it is obvious that the current status of equipment for chocolate package in our country is not as advanced as that at abroad, and it is not as advanced as the package level of developed countries both in the material and quality, so we have to work hard in the individualized package of chocolate, because some foreign valentine's day has been rooted in the young group of our country, and introverted lovers at ordinary times will also be full of courage on this day, and unstintingly generous to express their own feelings, announce their love to the world, and chocolate in valentine's day can naturally combine people, people will make good preparation, express their love boldly, and bravely express their expectation and loyalty for love. In order to express their love for each other, they will especially pay attention to individualized package, and some of them don't care about the contents, but the form is important, and many creative chocolate packages occur in supermarket and new supermarkets of all sizes, providing a space for young people to show love. "Individualized package structure can not only make others have a deep impression, but also leave a beautiful memory" [3]. According to the information, the price of chocolate package box is unequal, varying from about a few bucks to a few dozen yuan, and the recent sales volume is 
largely increased. As long as the package is individualized, the sale is good. In order to pursuit individualization, many consumers choose to customize gift box.

\section{PAY ATTENTION TO THE INDIVIDUALIZED DEMAND OF CONSUMERS For CHOCOLATE PACKAGE DESIGN}

While paying attention to the individualized performance of chocolate, it is also requested to realize that printing also has specific individualization requirements, and the printing materials, printing techniques, post-printing processing and the entire package plane design thereof attract consumers [2]. Because the expression of individualized expression characteristics with package appeals information is also interpreted in printing technology. For instance, Dove Chocolate in the market is the most familiar brand for people, and it is designed with external heart-shaped modeling, which can exactly meet young people's aspiration and deep love for each other through giving gifts, and when mainly promoting the chocolate for Valentine's Day, it is requested to pay special attention to the package modeling and the creative design of color, and create a romantic and meaningful warm atmosphere for the specific holiday, and the chocolate package design is not only the expression of love, but also make the mutual feelings of young people constantly sublimate when expressing their love, and individualized chocolate package design can not only gain the favor of the other party, but also vividly show and explain your unique aesthetics and friendship in the melting chocolate.

There are also various kinds of individualized expressions in the form, material and color of external package, etc., the product package specially designed by Designer Boyer Bastians for ice cream and chocolate brand-Australian Homemade deliberately avoided the adoption of typical high machine finish box to pack qualified chocolate, instead, the grey board made by recycled paper was adopted - although it is an extraordinary selection, it can meet "obtaining profits with principle" operation philosophy, i.e., use a part of business volume to support aborigine project. Such package is not only fixed, flexible and substantial, matte film is internally adopted, to prevent chocolate from leaving fat stains. The external cover of package box is silk-screen printing brand mark, and the other side of the external cover is attached with specific product information descriptions, while the chocolate is directly printed with various patterns of carotene, to show different tastes [6]. The color of plane design material related to product and the last printing technique are used to highlight its individualized expression.

Shanghai Golden Monkey Food Co., Ltd. is one of the three candy production factories nationwide, and its market occupation rate among similar products can reach to above $10 \%$. It has also constantly explored and made innovation, integrated marketing measures, and fully investigated the market positioning; the package of Golden Monkey chocolate is diversified, including the coin-shaped package, gold medal shaped package, peanut shaped package, gold ingot shaped package and Mars cup package, and the unique designed package form specific to different holidays and different consumption groups can attract consumers, because the price of chocolate is not the main competitive factors, and product innovation, taste and package are increasingly important, and this trend is especially highlighted internationally. Thus, individualized package design is an important carrier for chocolate to obtain market occupation rate, and meanwhile, the bridge for consumers to select certain brand of chocolate, and in order to study the individualized expression of chocolate package design, it is requested to highlight the group with individualized demand for chocolate specific to the difference of different consumption groups in aesthetic taste.

Except for meeting children's demand, children's chocolate package design should also cater to the aesthetic orientation of patents and the elderly, because the children's selection of chocolate will be participated with their parents and the elderly. On the basis of children's naïve and sincere nature, the perspective to recognize things is relatively simple and direct, and the bright, active and bouncing color can meet children's psychological demand. As for the color of chocolate package sold for children, high lightness and high purity colors, such as red, yellow, blue, green and other colors can be adopted, and contrast color, complementary color mixing measures can be used to express activeness, and then arouse emotional resonance [3], meanwhile, it should also consider the demand of parents and the elderly, they will see whether there are any educational toys therein, and whether the product can make children eat while playing. Designers should work hard in product appearance, color, pattern and other aspects, seize the curiosity of children, and attract children's attention visually, for instance, some current patterns on the children's chocolate package combine the cartoon figures from children's favorable cartoons, or the external package is made into all kinds of small toys, and after using it, children can also secondly use it as toys. Such package can not only attract children's attention, the tags favored by children therein can also exert the function of developing intelligence. Sometimes, it will also attract parents to stop and carefully observe it; besides, the package can also convince the adult to make decision on buying it for children. Such package has exerts its full function.

With respect to the enjoyment and educational demands in the design of children's chocolate package food, the package can be attached with simple matching toys, and while eating, they can also play these toys, so children can not only gain happiness through eating but also enjoy the fun therein. As for tasks with graphic design full of visual design, correspondence can be generated for funny cartoon figures, and these symbolic graphics can be specifically applied in package design, to cater to children's interest demand, so cartoon graph can largely reinforce visual impact; children cannot clearly distinguish some stuff, but they can clearly recognize cartoon graph and image, for instance, given the background of the currently hit show of Pleasant Goat and Grey Wolf, the product has considered the favor of children as a consumption group, and the patterns thereon are also the Pleasant Sheep, Big Grey Wolf, Little Grey and other figure photos from the cartoon favored by children, and it can meet children's visual aesthetic demand and interests, and better attract children's resonance in interests and emotions, the highlight of individualized package design is the silent promoter. Therefore, the package of children's chocolate should also advance with the times, and 
along with the development of era, different eras will release different eras of cartoon, and different means should be adopted to size children's mentality and design accordingly, "just as described in the time of a film called Someone Likes Spicy Food, anyone who observes fashion changes know that, sometimes, people's preference for design and color will change at a very unusual speed.'[4].

\section{The Selection Of Young People For INDIVIDUALIZED CHOCOLATE PACKAGE IS THE BRIDGE TO EXPRESS FEELINGS TO OTHERS}

From the perspective of adults, young people have bold and unrestrained emotions, and dare to do something unconventional or unorthodox, and are curious about all kinds of new stuff, and can also easily accept them, so special color combinations that can highlight individuality can better conform to the psychological traits of young people. As a group with active emotions, Valentine's Day has already become a good day for young people in China to express love to each other or further develop their relationship, and it has already become a holiday expected by young people per year. Young people romance, it is like the sweet love that never goes far away, young people will always generously express love on Valentine's Day, and rose and chocolate are the beautiful light spots of valentine's day. Rose will fade one day, but exquisite package and different forms of chocolate will kindly, truly and quietly wait and devote itself to all the sweet memories. Young people occupied the main consumption groups considering the sales of chocolate on Valentine 's Day; while expressing their love, they will invariably select chocolate as a gift for each other, so chocolate has also become a special food selected by young people to express love, and actually, chocolate will also be selected as a gift during many holidays, such as the grateful Mother's Day and the birthday party of friends, and chocolate has become the pronoun integrating elegance, happiness, warm and romance. Of course, the package design of chocolate can also show the individualized characteristics of people. Generally, when selecting chocolate as a gift, people will pursuit the novelty, peculiar, and fashionable individuality of chocolate package, which has become a kind of consumption psychology.

\section{CONCLUSION}

To sum up, in the intensely competitive target market, it is requested to confirm the objective of different consumption groups in the process of package design, and then meet different consumers in texture, structure and text arrangement, so as to make individualized consumption group generate rich purchasing desire, which can not only meet the demand of consumers, but also improve the sales profit of enterprises, and meanwhile, improve brand popularity. Meanwhile, individualized package design has obtained more and more attentions from designers of all countries worldwide, so it is worthy of carefully studying the individualized expression form of chocolate package design as a topic. The pursuit of individualized chocolate package design has become an important selection for reflecting commodity characteristics and promoting the sales of commodities.

\section{REFERENCES}

[1] Mu Cungang. Japanese Paper Box Package Creative Design [M]. Beijing: World Publishing Corporation Beijing Corporation, 2011.

[2] Wang Yansheng. Printing Process and Design. Beijing: Printing Industry Press. 2011

[3] [USA] Catherine. M. Fisher. Perfect Package Design. Translated by Liu Yumin and Xu Beibei. Shanghai. Shanghai People's Fine Arts Publishing House. 2008

[4] Research about the Psychology of Order Senses Decoration Art. [M]. Guangxi: Guangxi Arts Publishing House, 2009.

[5] Song Chunyan. Package Design [M]. Hebei: Hebei Fine Arts Publishing House. 2012.

[6] Garvin. Ambros. Package Design of Creative Brand. Beijing: China Youth Publishing House. 2012. 